\title{
Green Light Emission in Aluminum Oxide Powders Doped with Different Terbium Concentrations
}

\author{
L. Mariscal-Becerra. ${ }^{1, *}$, S. Carmona-Téllez ${ }^{2}$, R. Vázquez-Arreguín ${ }^{3}$, C. M. García-Rosas ${ }^{4}$, C. Falcony ${ }^{1}$, \\ H. Murrieta S. ${ }^{2}$, M.A. Sánchez-Alejo ${ }^{2}$ \\ ${ }^{1}$ Cinvestav, Gustavo A. Madero, Mexico \\ ${ }^{2}$ Institute of Physics, National Autonomous University of Mexico, Mexico \\ ${ }^{3}$ Superior School of Computer Sciences, National Polytechnic Institute, Mexico \\ ${ }^{4}$ Faculty of Sciences, National Autonomous University of Mexico, Mexico
}

Copyright $\mathrm{O} 2016$ by authors, all rights reserved. Authors agree that this article remains permanently open access under the terms of the Creative Commons Attribution License 4.0 International License

\begin{abstract}
Different emission intensities presented in aluminum oxide phosphors corresponding to different concentrations of doping performed with terbium are analyzed. The phosphors were synthesized by the evaporation technique and were characterized by photo and cathodoluminescence, $\mathrm{x}$-ray diffraction, and EDS techniques for different incorporation percentages of terbium as dopant; they show characteristic transitions in 494, 543, 587 and $622 \mathrm{~nm}$, corresponding to ${ }^{5} \mathrm{D}_{4} \rightarrow{ }^{7} \mathrm{~F}_{6},{ }^{5} \mathrm{D}_{4} \rightarrow{ }^{7} \mathrm{~F}_{5},{ }^{5} \mathrm{D}_{4} \rightarrow{ }^{7} \mathrm{~F}_{4}$ and ${ }^{5} \mathrm{D}_{4} \rightarrow{ }^{7} \mathrm{~F}_{3}$, respectively when they are excited with $\lambda_{\text {exc }}=$ $380 \mathrm{~nm}$ wavelength at room temperature. The results of XRD show the presence of $\alpha-\mathrm{Al}_{2} \mathrm{O}_{3}$ phases with peaks located at $2 \Theta=25.78,35.34,37.96,43.56,45.8,52.74,57.7,61.5$, $66.74,68.44,77.12$ and 80.94 , and the $\delta-\mathrm{Al}_{2} \mathrm{O}_{3}$ phase $2 \Theta=$ $32.82,45.8,61.36$ and 66.74 . These compounds were heat treated for two hours at $1100^{\circ} \mathrm{C}$. EDS analyzes indicate that these compounds have close to $60 \%$ oxygen around of $40 \%$ aluminum in the presence of terbium as dopant which indicates a stoichiometry close to the expected one for alumina.
\end{abstract}

Keywords Terbium, Luminescence, Powders, Aluminum Oxide

\section{Introduction}

The compounds of aluminum oxide doped with different elements like Europium[1], Manganese, Cerium[2], Lanthanum[3], Erbium, Praseodymium[4], Terbium[5], Iron, Chromium[6], Carbon[7], Ytterbium[8] and Thulium[9] have been studied carefully because of its excellent physical and chemical properties, such as luminescence, hardness, resistance to ionizing and thermal radiation, high dielectric constant and insulating characteristics. That's why they can be applied as dielectric materials with high refractive index and a wide bandgap, and in the field of optical coatings and metal-oxide semiconductor devices for next generation devices; those are just a few reasons why alumina has a large potential for its wide variety of applications.

The compounds of aluminum oxide doped with rare earths are obtained by different techniques such as spray pyrolysis $[2,5]$, organic acids combustion[3], sol-gel[4,8], pulverizing-metallurgy[6], laser ablation sputtering $[10,11]$, dissolvent evaporation[1] and other more[12-17]. These have been developed for the various compounds $\mathrm{Al}_{2} \mathrm{O}_{3}$ that are doped in simple experimental conditions. Oxides doped with rare earths are of the most promising; because the $4 \mathrm{f}$ orbitals are protected very effectively by the electrons of the $5 \mathrm{~s} 25 \mathrm{p} 6$ outer layers, this is why the states originating from the different configurations $4 \mathrm{f}^{\mathrm{n}}$ are only slightly affected by the surrounding ions and remain virtually unchanged for an specific ion in all its compounds, according to this electronic configuration, $\mathrm{f}-\mathrm{f}$ transitions have narrow and sharp peaks observed in the optical absorption and emission spectra.

The $\mathrm{Al}_{2} \mathrm{O}_{3}$ is a material with a great technological importance due to its optical transparency from the ultraviolet to the near infrared; and its excellent mechanical properties and chemical stability, presenting different crystalline phases at different temperatures; the phase $\alpha-\mathrm{Al}_{2} \mathrm{O}_{3}$ being the most stable.

In this work optical, structural and morphological characteristics of aluminum oxide powders doped with different concentrations of terbium chloride are presented; the samples were obtained through simple evaporation technique at a temperature of $1100^{\circ} \mathrm{C}$ to obtain a luminescent material in the green region of the spectra.

\section{Materials and Methods}

The aluminum oxide $\mathrm{Al}_{2} \mathrm{O}_{3}$ powder doped with different percentages of $\mathrm{TbCl}_{3}$ was obtained through the evaporation technique [1]. The solution was obtained by dissolving in $5 \mathrm{ml}$ of deionized water $\left(18 \mathrm{M} \Omega \mathrm{cm}^{-1}\right)$, an appropriate 
quantity of $\mathrm{Al}\left(\mathrm{NO}_{3}\right)_{3}$ and $\mathrm{TbCl}_{3}$ to $(3,5,7,10,12$ and 15 at.\% mol). Each of the compounds were dried at $200^{\circ} \mathrm{C}$ and subsequently calcined at $1100^{\circ} \mathrm{C}$ for two hours and tempered at room temperature; its structure was analyzed by X-ray diffraction (XRD) using a Siemens D5000 diffractometer with $1,540 \AA(\mathrm{Cu} \mathrm{K \alpha})$ operating at $30 \mathrm{keV}$; the chemical composition of the powders was measured using energy dispersive spectroscopy (EDS) with a model Leica Cambridge Stereoscan 440 Electron Microscope equipped with an X-ray detector with beryllium window. The luminescence spectra were obtained with a Perkin-Elmer LS-50B; Photoluminicence (PL) emission spectra were obtained using a continuous $\lambda_{\text {exc }}=380 \mathrm{~nm}$ wavelength using a UV $8 \mathrm{~W}$ mercury lamp, model UVGL-25; cathodoluminescence (CL) measurements were performed in a stainless steel vacuum chamber with a cold cathode electron gun (Luminoscope, model ELM-2 MCA, RELION Co.). Powders were placed inside the vacuum chamber and evacuated to $\sim 10^{-2}$ Torr. The electron beam was deflected through a $90^{\circ}$ angle to focus onto the luminescent film normal to the surface; the diameter of the electron beam on the powders was $3 \mathrm{~mm}$ approximately. The emitted light was collected by an optical fiber and fed into a SPEX Fluoro-Max-P spectrophotometer. All measurements were carried out at room temperature.

\section{Results and Discussion}

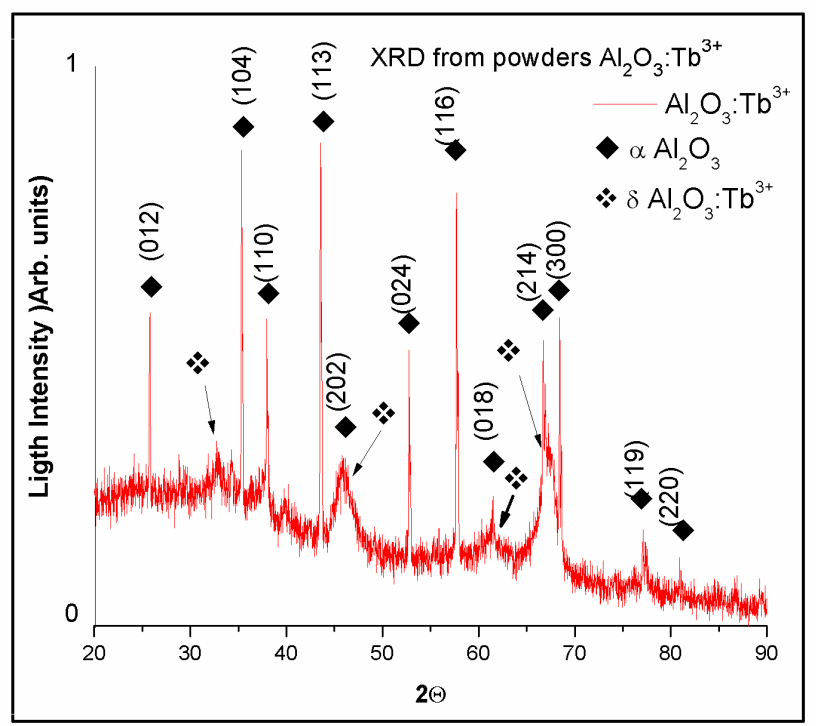

Figure 1. XRD measurements from $\mathrm{Al}_{2} \mathrm{O}_{3}: \mathrm{Tb}^{3+}$ synthesized at $1100{ }^{\circ} \mathrm{C}$.

The crystal structure of the powders was analyzed by $\mathrm{X}$-ray diffraction (XRD) Show in Figure 1 are the diffraction plot of $\mathrm{Al}_{2} \mathrm{O}_{3}: \mathrm{Tb}^{3+}$ phosphors. Previous studies have shown that various crystalline phases are present in $\mathrm{Al}_{2} \mathrm{O}_{3}$ compounds, these phases $\alpha-\mathrm{Al}_{2} \mathrm{O}_{3}, \gamma-\mathrm{Al}_{2} \mathrm{O}_{3}$ and $\delta-\mathrm{Al}_{2} \mathrm{O}_{3}$ appear when this compound has been thermally treated from $800^{\circ} \mathrm{C}$ to $1000^{\circ} \mathrm{C}$, whereas phase $\alpha-\mathrm{Al}_{2} \mathrm{O}_{3}$ occurs at temperatures above 1000 to $1200^{\circ} \mathrm{C}$ [19] The graph shows that powders $\mathrm{Al}_{2} \mathrm{O}_{3}: \mathrm{Tb}^{3+}$ have the crystal phase $\alpha-\mathrm{Al}_{2} \mathrm{O}_{3}$ with peaks located at $2 \Theta=25.78,35.34,37.96,43.56,45.8,52.74$, $57.7,61.5,66.74,68.44,77.12$ and 80.94 , which are associated with the planes (012), (104), (110), (113), (202), (024), (116), (018), (214), (300), (119) and (220), according to diffraction JCPDS card $81-1667$. The $\alpha-\mathrm{Al}_{2} \mathrm{O}_{3}$ phase is a hexagonal primitive cell $[19,20]$, with lattice parameters $\mathrm{a}=$ $\mathrm{b}=4.75999 \AA \mathrm{c}=12.99481 \AA$ [21]. In this compound are also identified peaks corresponding to the phase $\delta-\mathrm{Al}_{2} \mathrm{O}_{3}$, in $2 \Theta=32.82,45.8,61.36$ and 66.74 , associated with the planes (220), (400), (511) and (440) according to JCPS card $50-0741$, this phase is cubic with lattice parameter a $=7.939$ $\AA$.

The crystal size was estimated by Sherer's formula [22]:

$$
T=\frac{0.9 \lambda}{B \sin \Theta_{B}}
$$

Where: $T$ represents the crystal size, $\lambda$ is the wavelength radiation $\mathrm{CuK} \alpha(1.5406 \AA), \mathrm{B}$ is the half width of the diffraction peak and $\theta_{\mathrm{B}}$ the Bragg's angle measured in radians; sizes calculated for the phase $\delta-\mathrm{Al}_{2} \mathrm{O}_{3}$, is $32.47 \mathrm{~nm}$ in $\theta=32.72$, in $\theta=37.88$ its size is of $40.33 \mathrm{~nm}$, at $\theta=45.8$ its value is $20.8 \mathrm{~nm}$, at $\theta=61.48$ is $26.3 \mathrm{~nm}$, at $\theta=66.64$ is $17.98 \mathrm{~nm}$ and at $\theta=77.1$ is $22.22 \mathrm{~nm}$ [23]. It is important to note, that no significant differences in the XRD patterns among powders $\mathrm{Al}_{2} \mathrm{O}_{3}$ and those doped with $\mathrm{Tb}^{3+}$ are detected, probably due to the low percentage of terbium; because of this it is not surprising that there are not large clear differences between $\mathrm{Al}_{2} \mathrm{O}_{3}$ powders and $\alpha-\mathrm{Al}_{2} \mathrm{O}_{3}$ phase doped with terbium. The EDS measurements indicate the presence of aluminum, oxygen and a minimum part of terbium, EDS results are shown in table 1, in the table the results of the powders correspond to $12 \%$ of doped with terbium.

Even though EDS is not a quantitative technique it is useful to estimate the chemical composition of samples, EDS measurements on doped and non-doped phosphors were performed and the results are listed in Table 1. In the case of doped samples, it is shown just the 12 at. \% of $\mathrm{Tb}$, because is which has the highest luminescence intensity. According to the expected stoichiometry for aluminum oxide (a relation of 3 to 2 of the oxygen to aluminum), a presence of $60 \%$ of oxygen and $40 \%$ of aluminum, is observed. In the case of doped samples, there is an apparent substitution of $\mathrm{Al}$ ions by $\mathrm{Tb}^{3+}$, but in a low quantity, this effect is observed in some previous reports in some host materials, techniques and dopants $[3,18,20,23]$.

Table 1. Measurement of percentage and weight of aluminum, oxygen and terbium for EDS the phosphors $\mathrm{Al}_{2} \mathrm{O}_{3}$ and $\mathrm{Al}_{2} \mathrm{O}_{3}: \mathrm{Tb}^{3+}$ at $12 \%$ doped.

\begin{tabular}{|c|c|c|c|c|c|}
\hline \multicolumn{3}{|c|}{$\mathrm{Al}_{2} \mathrm{O}_{3}$} & \multicolumn{3}{c|}{$\mathrm{Al}_{2} \mathrm{O}_{3}: \mathrm{Tb}^{3+}$} \\
\hline Element & $\begin{array}{c}\text { weight } \\
\%\end{array}$ & atomic \% & Element & weight\% & $\begin{array}{c}\text { atomic } \\
\%\end{array}$ \\
\hline $\mathrm{O}$ & 49.59 & 62.39 & $\mathrm{O}$ & 43.60 & 60.00 \\
\hline $\mathrm{Al}$ & 50.41 & 37.61 & $\mathrm{Al}$ & 47.51 & 38.76 \\
\hline $\mathrm{Tb}$ & ---- & ---- & $\mathrm{Tb}$ & 8.89 & 1.24 \\
\hline Total & 100.00 & & Total & 100.00 & \\
\hline
\end{tabular}




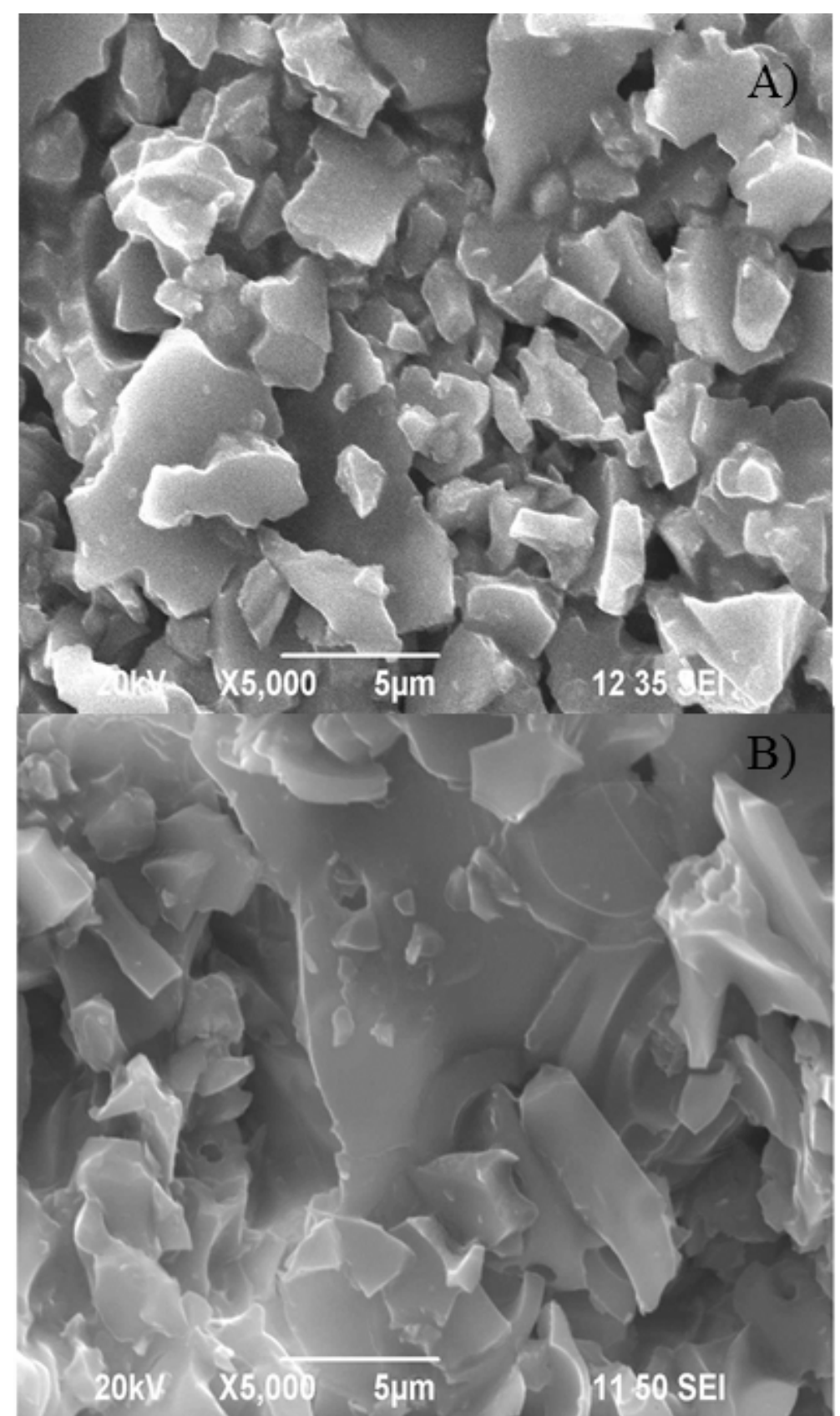

Figure 2. A) $\mathrm{SEM}$ image of $\mathrm{Al}_{2} \mathrm{O}_{3}$ undoped powder, B) $\mathrm{SEM} \mathrm{AL}_{2} \mathrm{O}_{3}: \mathrm{Tb}^{3+}$ powder.

Fig. 2 shows two SEM images of $\mathrm{Al}_{2} \mathrm{O}_{3}$ and $\mathrm{Al}_{2} \mathrm{O}_{3}: \mathrm{Tb}^{3+}$ phosphors annealed at $1100^{\circ} \mathrm{C}$, it can be observed that the powder particles grow in a sheet form, and have sizes from 1 to $5 \mu \mathrm{m}$, although smaller powder sizes of about $100 \mathrm{~nm}$ are also observed. The size is determined, largely, by the grinding process of the powders. No difference in size or morphology was found between doped and none-doped powders. These micron-sized powders are particularly good for various technological applications like lighting devices. 


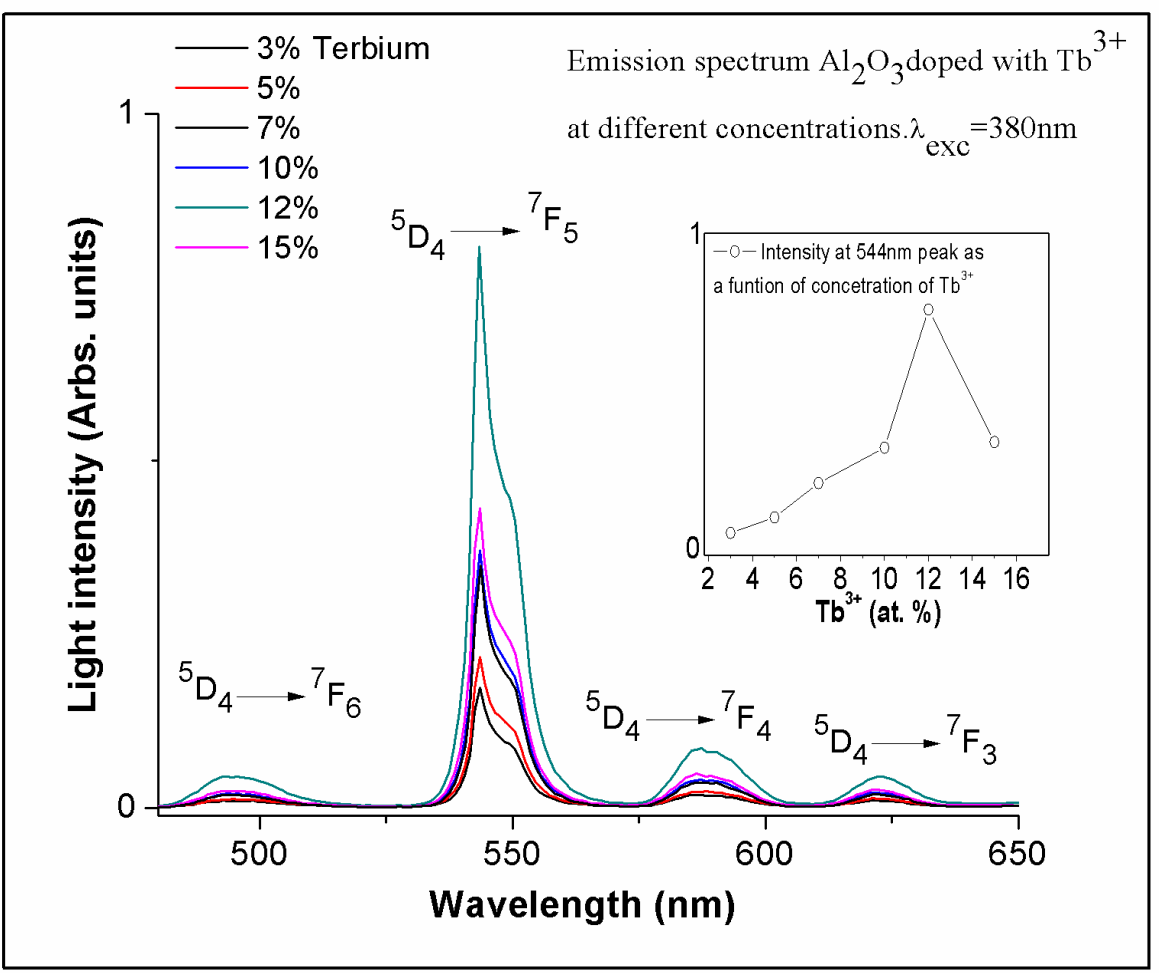

Figure 3. Luminescence intensity as a function of $\mathrm{Tb}^{3+}$ ion concentration into $\mathrm{Al}_{2} \mathrm{O}_{3}: \mathrm{Tb}^{3+}$ powders.

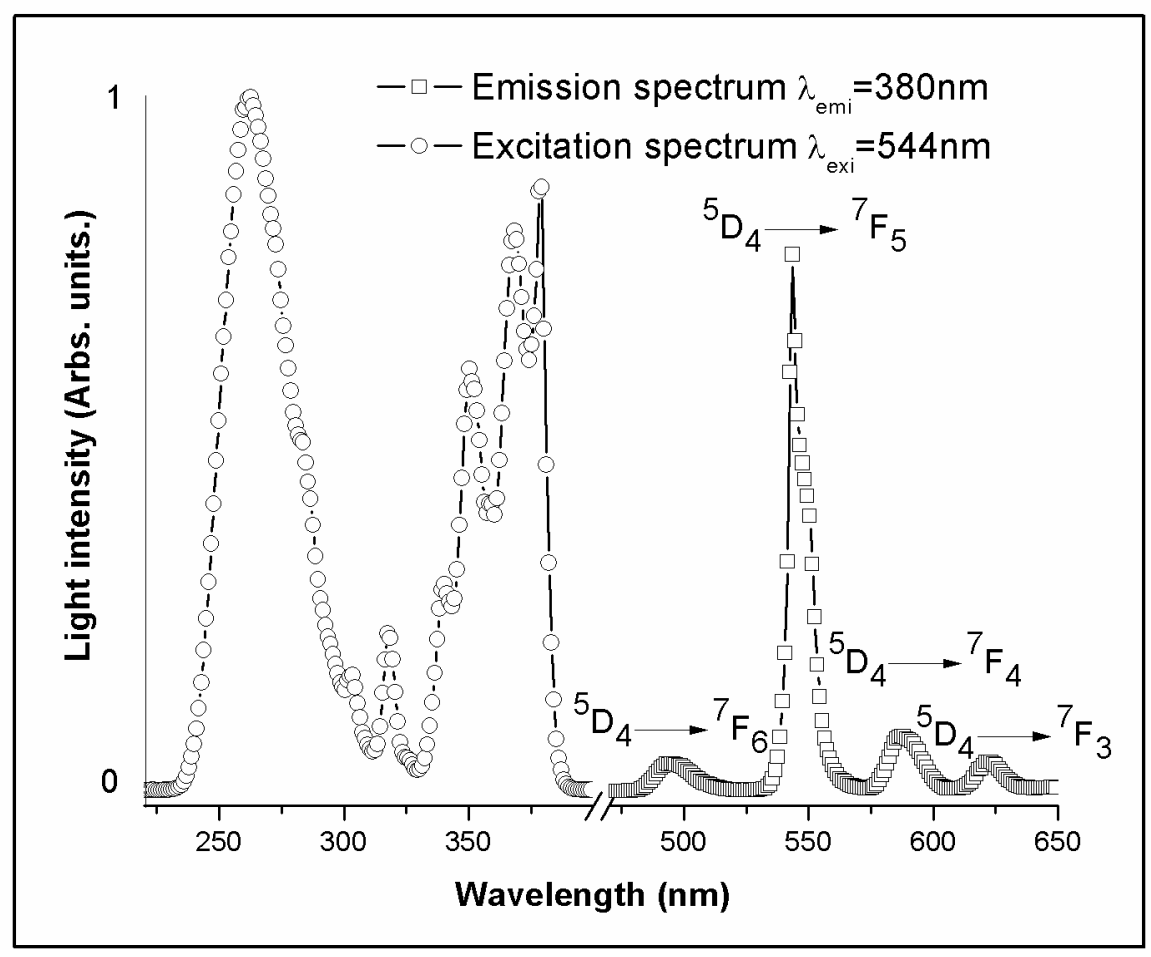

Figure 4. Comparison between emission and excitation spectrum for $\mathrm{Al}_{2} \mathrm{O}_{3}: \mathrm{Tb}^{3+}$ phosphors. 


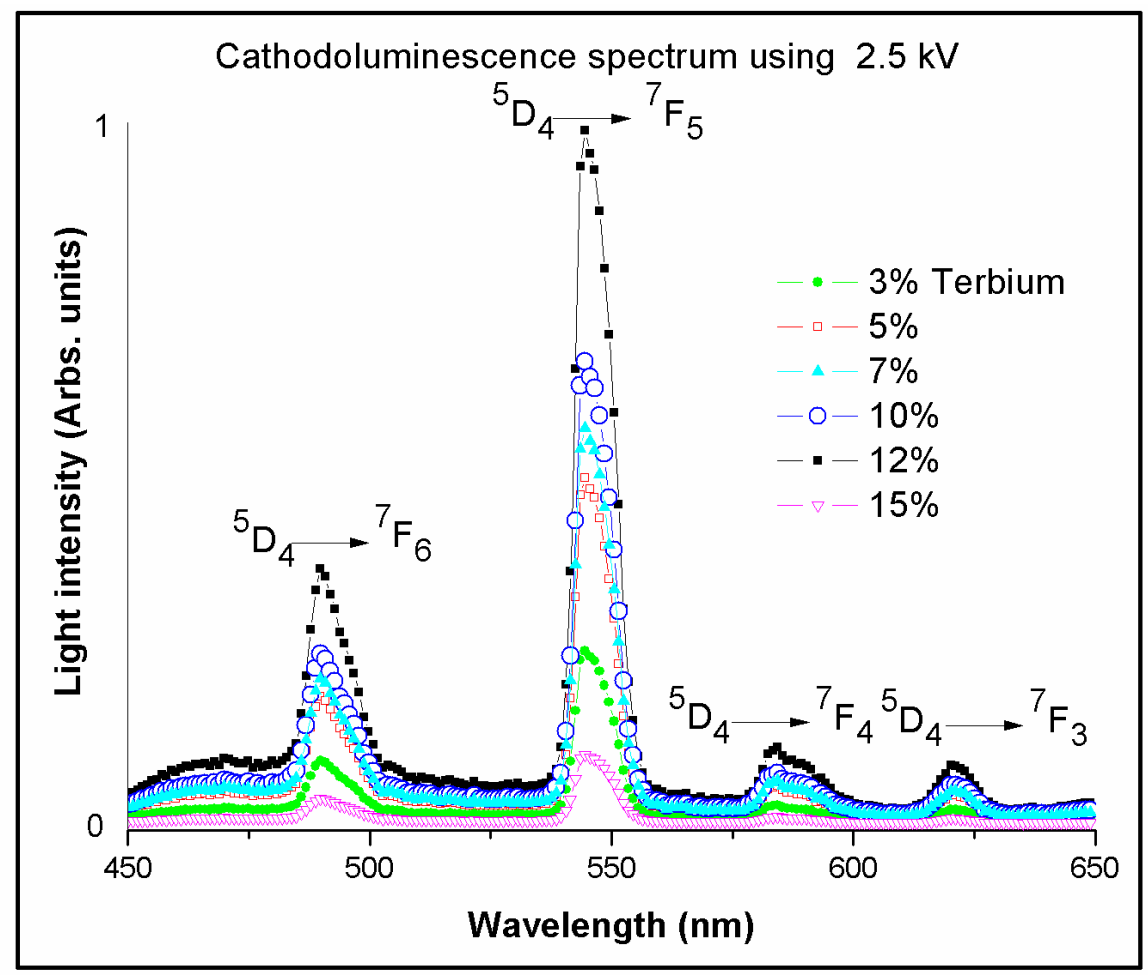

Figure 5. $\mathrm{CL}$ emission spectra intensity as a function of $\mathrm{Tb}^{3+}$ ion concentration into $\mathrm{Al}_{2} \mathrm{O}_{3}: \mathrm{Tb}^{3+}$ powders.

The normalized emission spectra were obtained for the aluminum oxide powders doped with percentages from 3 at $\%$ to 15 at $\%$ of terbium and are shown in Figure 3. In the graph are shown transitions for the $\mathrm{Tb}^{3+}$ ion, which appear at $494,543,587$ and $622 \mathrm{~nm}$ and corresponding to ${ }^{5} \mathrm{D}_{4} \rightarrow{ }^{7} \mathrm{~F}_{6}$, ${ }^{5} \mathrm{D}_{4} \rightarrow{ }^{7} \mathrm{~F}_{5},{ }^{5} \mathrm{D}_{4} \rightarrow{ }^{7} \mathrm{~F}_{4}$ and ${ }^{5} \mathrm{D}_{4} \rightarrow{ }^{7} \mathrm{~F}_{3}[2,5,17,18]$; respectively, using a continuous excitation radiation of $380 \mathrm{~nm}$ wavelength at room temperature, The dominant peak for these spectra is the one associated with the transition ${ }^{5} \mathrm{D}_{4}$ to ${ }^{7} \mathrm{~F}_{5}$ at $544 \mathrm{~nm}$, which gives the characteristic green light emission identified with the presence of $\mathrm{Tb}^{3+}$ ions. The emission intensity for different terbium doping concentrations are shown in Figure 3 indicating that this is increased by the increase of doping percentage, the best efficiency is presented with the percentage of $12 \%$ is presented the best efficiency, while 14\% dopant diminishes in intensity because they present quenching effect associated with energy transfer among dopant ions.

In Figure 4 the excitation and emission spectra are shown, in the excitation spectra are observed that exist some peaks capable to excite $\mathrm{Tb}^{3+}$ ions, the higher peaks that could excite are 260 and $380 \mathrm{~nm}$; the broad excitation band centered at $260 \mathrm{~nm}$, is commonly ascribed to the $\mathrm{O}-\mathrm{Tb}$ charge-transfer transition (ligand to metal charge transfer). the general behavior of these results is similar to that reported previously in which a dependence of the photoluminescence intensity is correlated with the incorporation efficiency of the $\mathrm{Tb}$ ions into the aluminum oxide matrix; all of them show a band of high intensity at $260 \mathrm{~nm}$, additionally the $\mathrm{Al}_{2} \mathrm{O}_{3}: \mathrm{Tb}^{3+}$ powder spectrum presents other peaks at $303,318,340.350,368$ and $380 \mathrm{~nm}$. The intensity in $260 \mathrm{~nm}$ is significantly more intense than the forbidden transitions centered at $303 \mathrm{~nm}\left({ }^{5} \mathrm{I}_{8} \rightarrow{ }^{7} \mathrm{~F}_{6}\right.$, $\left.{ }^{5} \mathrm{~F}_{4},{ }^{5} \mathrm{~F}_{5},{ }^{5} \mathrm{H}_{4}\right), 318 \mathrm{~nm}\left({ }^{7} \mathrm{~F}_{6} \rightarrow{ }^{5} \mathrm{H}_{5},{ }^{5} \mathrm{H}_{6}\right), 340 \mathrm{~nm}\left({ }^{7} \mathrm{~F}_{6} \rightarrow{ }^{5} \mathrm{H}_{7}\right.$, $\left.{ }^{5} \mathrm{D}_{1}\right), 350 \mathrm{~nm}\left({ }^{5} \mathrm{~L}_{7,8} \rightarrow{ }^{7} \mathrm{~F}_{6},{ }^{5} \mathrm{G}_{3}\right), 368 \mathrm{~nm}\left({ }^{7} \mathrm{~F}_{6} \rightarrow{ }^{5} \mathrm{~L}_{9},{ }^{5} \mathrm{D}_{2},{ }^{5} \mathrm{G}_{5}\right)$ and $380 \mathrm{~nm}\left({ }^{7} \mathrm{~F}_{6} \rightarrow{ }^{5} \mathrm{~L}_{10},{ }^{5} \mathrm{G}_{6},{ }^{5} \mathrm{D}_{3}\right)$, as can be seen in the figure 4 , which describes the charge-transfer transition that occurs between the ligand and the metal (O-Al), the most luminescent intensity with 12 at. $\%$ of $\mathrm{Tb}^{3+}$ in the powders of $\mathrm{Al}_{2} \mathrm{O}_{3}: \mathrm{Tb}^{3+}$, those phosphors have high quantum yield efficiency about 25.97.

Fig. 5 shows the CL spectrum of $\mathrm{Al}_{2} \mathrm{O}_{3}: \mathrm{Tb}^{3+}$ powders, during $\mathrm{CL}$ measurements the anode voltage and the beam current were kept constant. The spectrum consist of a number of well resolved peaks at 490,544, 590, and $622 \mathrm{~nm}$, which are assigned to ${ }^{5} \mathrm{D}_{4}$ to ${ }^{7} \mathrm{~F}_{6},{ }^{7} \mathrm{~F}_{5},{ }^{7} \mathrm{~F}_{4}$ and ${ }^{7} \mathrm{~F}_{3}$, of the $\mathrm{Tb}^{3+}$ ion transitions respectively. The most intense emission occurs at $544 \mathrm{~nm}$ and is due to ${ }^{5} \mathrm{D}_{4}$ to ${ }^{7} \mathrm{~F}_{5}$ transition. Similar results have been obtained earlier for oxide doped with $\mathrm{Tb}^{3+}$, and the results are consistent with those previously mentioned [3, 18,23], cathodoluminescence results obtained from all the used concentrations of terbium as dopant, are consistent with the photoluminescence when they were excited using continuous $380 \mathrm{~nm}$ wavelength radiation having its maximum at 12 at. \% (these results are not shown in this report).

Fig. 6 shows the CIE diagram (Commission International de l'éclairage) [24] which defines the three primary colors of color displays, and from these the combination of different colors is obtained to generate secondary colors in its different shades, depending on their individual coordinates $(\mathrm{x}, \mathrm{y})$. For $\mathrm{Al}_{2} \mathrm{O}_{3}: \mathrm{Tb}^{3+}$ powders, when excited with $380 \mathrm{~nm}$, the coordinates are $(x=0.31, y=0.5111)$, according to the 
CIE diagram, they are located in the green color, being these results comparable to previous ones reported for $\mathrm{Tb}^{3+}$ in a variety of different hosts.[2,3,16].

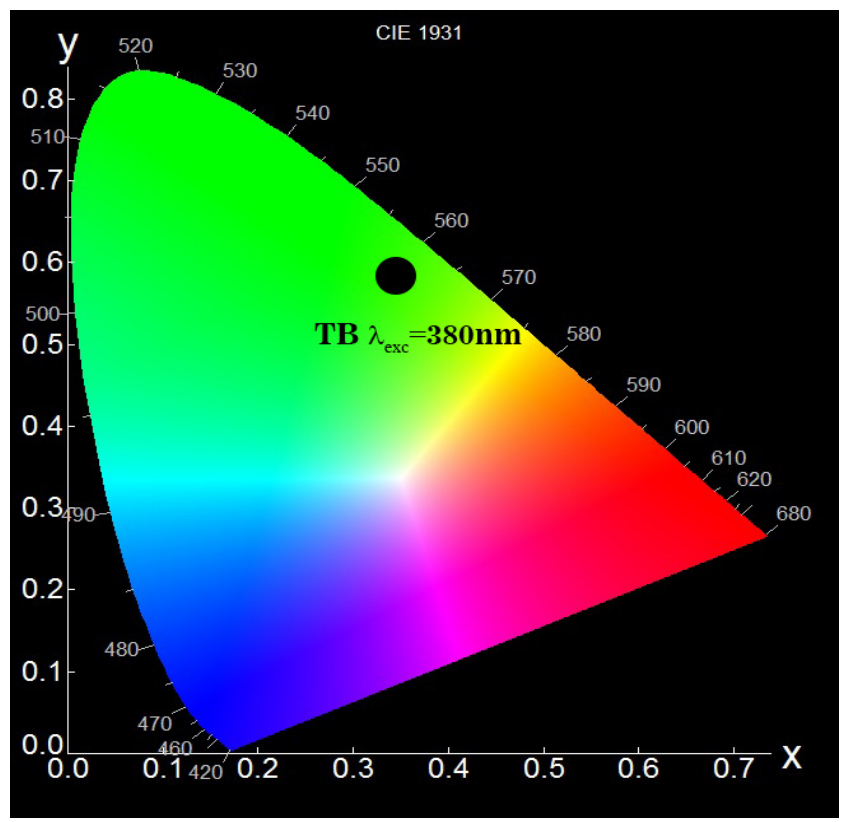

Figure 6. CIE diagram $\mathrm{Al}_{2} \mathrm{O}_{3}: \mathrm{Tb}^{3+}$ powders.

\section{Conclusions}

Analysis of the aluminum oxide powder doped with terbium in different concentrations indicates from the results of X-ray diffraction that these powders are polycrystalline and that phase $\alpha-\mathrm{Al}_{2} \mathrm{O}_{3}$ peaks located at observed $2 \Theta=25.78,35.34,37.96,43.56,45.8,52.74,57.7$, $61.5,66.74,68.44,77.12$ and 80.94 , and phase $\delta-\mathrm{Al}_{2} \mathrm{O}_{3}$, in $2 \Theta=32.82,45.8,61.36$ and 66.74 are present. The photoluminescence spectrum shows that is associated with terbium transitions and better emission efficiency occurs when is used 12 at. \% of dopant; these phosphors have a quantum yield efficiency around 25.97, using a continuous $380 \mathrm{~nm}$ wavelength as excitation radiation, this wavelength is of less energy than $260 \mathrm{~nm}$ wavelength, which is commonly used in previous reports; therefore if could get low cost LEDs for green light; CL results also show that the transitions are associated with $\mathrm{Tb}^{3+}$ ion. EDS analysis shows that aluminum oxide corresponds to the stoichiometric formula $\mathrm{Al}_{2} \mathrm{O}_{3}$, due to these results it can be considered that this type of compound is a good candidate to have green light and its preparation is simple and of low economic cost.

\section{Acknowledgements}

The authors wish to acknowledge the technical assistance of Z. Rivera, M. Guerrero and A. Soto from physics department of CINVESTAV-IPN. The authors also thank
DGAPA-UNAM, and CONACyT to financial support.

\section{REFERENCES}

[1] Preparation and thermoluminescence properties of aluminum oxide doped with europium, J. Azorín, A. Esparza, C. Falcony, T. Rivera, M. García and E. Martínez, Radiation Protection Dosimetry Vol. 100, Nos 1-4, pp. 277-279 (2002).

[2] White light generation in rare-earth-doped amorphous films produced by ultrasonic spray pyrolysis aluminum and hafnium oxide films doped with $\mathrm{CeCl}_{3} / \mathrm{TbCl}_{3} / \mathrm{MnCl}_{2}$, Rafael Martínez-Martínez, Edgardo Yescas, Enrique Álvarez, Ciro Falcony, Ulises Caldiño, Advances in Science and Technology Vol. 82 (2013) pp 19-24.

[3] Synthesis and photoluminescence properties of $\mathrm{La}_{1 \times \mathrm{x}} \mathrm{AlO}_{3: \mathrm{x}} \mathrm{Tb}^{3+}$ green phosphors for white LEDs, S.J. Yoona, S.J.Dhobleb, K.Parka, Ceramics International 40(2014)4345-4350.

[4] Optical spectra of triply-charged rare-earth ions in polycrystalline corundum, A. A. Kaplyanskiĩ, A. B. Kulinkin, A. B. Kutsenko, S. P. Feofilov, R. I. Zakharchenya, and T. N. Vasilevskaya, Physics of the solid state volume 40, number 8 august 1998.

[5] White Light Emitting Transparent Double Layer Stack of $\mathrm{Al}_{2} \mathrm{O}_{3}: \mathrm{Eu}^{3+}, \mathrm{Tb}^{3+}$, and $\mathrm{Ce}^{3+}$ Films Deposited by Spray Pyrolysis, S. Carmona Téllez, C. Falcony, M. Aguilar Frutis, G. Alarcón Flores, M. Garí1a Hipólito, and R. Martínez Martínez, ECS Journal of Solid State Science and Technology, 2 (6) R111-R115 (2013).

[6] Characterization of Fe-Cr- $\mathrm{Al}_{2} \mathrm{O}_{3}$ Composites Fabricated by Powder Metallurgy Method with Varying Weight Percentage of Alumina, Saidatulakmar Shamsuddin, Shamsul Baharin Jamaludin, Zuhailawati Hussain and Zainal Arifin Ahmad, Journal of Physical Science, Vol. 19(1), 89-95, 2008.

[7] Highly sensitive thermoluminescent carbon doped nanoporous aluminum oxide detectors, W. M. de Azevedo, G. B. de Oliveira, E. F. da Silva Jr, H. J. Khoury and E. F. Oliveira de Jesus, Radiation Protection Dosimetry (2006), Vol. 119, No. 1-4, pp. 201-20.

[8] $\mathrm{Yb}^{3+}$ energy levels in $\square-\mathrm{Al}_{2} \mathrm{O}_{3}$, J.K. Krebs and U. Happek, Journal of Luminescence 94-95 (2001) 65-68.

[9] Thermoluminescence study of aluminum oxide doped with therbium and thulium, V.S.M. Barros, W.M. de Azevedo, H.J. Khoury, M.E.A. Andrade, P. Linhares Filho, Radiation Measurements 45 (2010) 435-437.

[10] A comparative study of rare earth-iron thin films prepared by TEA $\mathrm{CO}_{2}$ and excimer laser ablation deposition, L.A Stone, H.V Snelling and A.G Jenner, Volumes 109-110, 1 February 1997, Pages 389-392.

[11] Low temperature deposition of $\alpha-\mathrm{Al}_{2} \mathrm{O}_{3}$ thin films by sputtering using a $\mathrm{Cr}_{2} \mathrm{O}_{3}$, P. Jin, G. XU, K. Yoshimura, J. Alami and U. Helmersson, Template Journal of Vacuum Science \& Technology A 20, 2134 (2002).

[12] Substrate dependence on the optical properties of $\mathrm{Al}_{2} \mathrm{O}_{3}$ films grown by atomic layer deposition, Y. Kim, S.M. Lee, C.S. Park, S.I. Lee and M. Y. Lee, Applied Physics Letters 71, 
3604 (1997).

[13] $\mathrm{Al}_{2} \mathrm{O}_{3}$ thin films from aluminum dimethylisopropoxide by metal-organic chemical vapour deposition, Davide Barreca, Giovanni A. Battiston, Rosalba Gerbasi and Eugenio Tondello, J. Mater. Chem., 2000, 10, 2127-2130.

[14] Crystallization, phase transition and optical properties of the rare-earth-doped nanophosphors synthesized by chemical deposition, X. Y. Chen, L. Yang, R. E. Cook, S. Skanthakumar, D. Shi and G. K. Liu, Nanotechnology 14 (2003) 670-674.

[15] Conformal aluminum oxide coating of high aspect ratio structures using metalorganic chemical vapor deposition, $\mathrm{F}$. Wiest, V. Capodieci, O. Blank, M. Gutsche, J. Schulze, I. Eisele, J. Matusche, and U.I. Schmidt, Thin Solid Films 496 (2006) $240-246$.

[16] Terbium Implanted AlN and Photoluminescence Properties, Fei Lu, R. Carius, A. A. Alam and M. Heuken, Journal of the Korean Physical Society, Vol. 46, May 2005, pp. S48-S51.

[17] Time-dependence of luminescence of nanoparticles of $\mathrm{Eu}_{2} \mathrm{O}_{3}$ and $\mathrm{Tb}_{2} \mathrm{O}_{3}$ deposited on and doped in alumina, A. Gedanken, R. Reisfeld, L. Sominski, Z. Zhong, Yu. Koltypin, Applied physics letters volume 77, number 714 august 2000.

[18] Thermoluminescence and optically stimulated luminescence characteristics of $\mathrm{Al}_{2} \mathrm{O}_{3}$ doped with $\mathrm{Tb}$, J.V. Soares , C.F.
Gugliotti , Y.S. Kawashima , S.H. Tatumi , J.C.R. Mittani, Radiation Measurements (2014).

[19] Electronic structure of $\alpha-\mathrm{Al}_{2} \mathrm{O}_{3}$ slabs: A local environment study, Germán N. Darriba, Ricardo Faccio, Mario Rentería, Physica B: Condensed Matter Volume 407, Issue 16, 15 August 2012, Pages 3093-3095.

[20] Nano $\alpha-\mathrm{Al}_{2} \mathrm{O}_{3}$ Powder Preparation by Calcining an Emulsion Precursor Yu-Chen Lee, Shaw-Bing Wen, Liang Wenglin and Chih-Peng Lin, J. Am. Ceram. Soc., 90, 6, 2007. Volume 90, Issue 6, pages 1723-1727, June 2007.

[21] Rietveld analysis of powder patterns obtained by TOF neutron diffraction using cold neutron sources, F. Izumi, $\mathrm{H}$. Asano, H. Murata and N. Watanabe, J. Appl. Cryst., 20, 5, 1987.

[22] Elements of X-Ray Diffraction, B.D. Cullit, S.R. Stock, Prentice-Hall Inc., p. 388, 2001.

[23] Blue-Green Emission in Terbium-Doped Alumina ( $\left.\mathrm{Tb}: \mathrm{Al}_{2} \mathrm{O}_{3}\right)$ Transparent Ceramics, Elias H. Penilla , Yasuhiro Kodera, and Javier E. Garay, Adv. Funct. Mater. 2013, 23, 6036-6043.

[24] Spectral Distribution of Typical Daylight as a Function of Correlated Color Temperature, Deane B. Judd, David L. Macadam, Günter Wyszecki, H. W. Budde, H. R. Condit, S. T. Henderson, and J. L. Simonds, Journal of Optical Society of America, 54, (1964) 1031. 